\title{
Interrelation of indicators of efficiency of throws and individually typological properties of the higher nervous activity and sensorimotor functions of athletes in basketball
}

\author{
YunFan $\mathrm{Li}^{1}$, Iliya Cherkashin ${ }^{2,3^{*}}$, Elena Cherkashina ${ }^{2}$, and Victoria Kopylova ${ }^{4}$ \\ ${ }^{1}$ Shenzhen University, China \\ ${ }^{2}$ North-East federal university, Russia \\ ${ }^{3}$ Yakut state agricultural academy, Russia \\ ${ }^{4}$ Churapcha state institute of physical education and sports, Russia
}

\begin{abstract}
The article discusses the results of research of interrelation between individually typological properties of the higher nervous activity, sensorimotor functions and the efficiency of throws into the basket of students-basketball players. Study of psychophysiological condition of athletes in basketball is very important because motor skills are directly related to psychophysiological characteristics. With the help of computer system "Diagnost-1" (authors N.V.Makarenko, V.S.Lizogub) data characterizing individually typological properties of the higher nervous activity and sensorimotor functions of basketball players were obtained. Data analysis proves that the most of surveyed athletes have strong and movable type of the higher nervous activity. The efficiency of throws into the basket and psychophysiological condition of athletes are interrelated tightly. It was proved by the results of correlation analysis of quantities of psychological, physiological and pedagogical tests, namely, indicators of individual typological properties of higher nervous activity and sensorimotor functions and nine tests on determination of the efficiency of throws by students-basketball players.
\end{abstract}

Psychophysiological functions are the biological foundation of individual typological properties of the higher nervous activity that can be used in differential diagnosis of the functional state of the human body. Because of fatigue of nerve centers in conditions of muscular activity functional condition of psychophysiological functions can be a sensitive indicator of the development of fatigue and overstrain of athletes [1,2]. Perception and processing of visual information for athletes is an important property of psychophysiological functions. The speed of visual response depends on a number of factors that determine the effectiveness of the performance of the athlete: afferent, receptor part of the perception of information, the central part of the processing of visual

\footnotetext{
* Corresponding author: 706037@mail.ru
} 
information on the level of the central nervous system and efferent, executive part of neuropsychophysiological response $[3,4]$.

Activities in situational sports, which include sports games, requires those involved in the rapid adoption of error-free decisions in a rapidly changing environment [5]. That is why the activity of basketball players is frequently characterized as "operational" or "operator" [5-8]. Many works analysis let us make the conclusion that the activity of nervous processes during making decision in changing conditions is important and is necessary for competitive activity in sport games $[5,6,9,10,11]$. Mobility of nervous processes directly affects the ability to form a variable motor stereotype, reactions of athletes in basketball as a sport game [12-14].

It is known that the success of competitive activity depends on the speed of sensorimotor response, which largely determines the functional condition of the central nervous system $[4,5,15]$.

The study of the psychophysiological condition of athletes is important in basketball where motor skills are directly related to psychophysiological characteristics. According to many experts studying the psychophysiological functions of athletes, representatives of different sports with different qualifications, experience of research of psychophysiological diagnostics has the following General scheme: definition of individual-typological properties of the nervous system and neural functions of the athlete, assessment of cognitive function of the athlete, diagnosis of level of anxiety, emotional stability and characteristics of personal qualities of the athlete $[5,16,17,18]$.

Data characterizing individual typological properties of higher nervous activity and sensorimotor functions of athletes were obtained as a result of a study of psychophysiological functions of Shenzhen University basketball players with computer system "Diagnost-1” (authors N.V.Makarenko, V.S.Lizogub) [19] (table 1).

Table 1. Indicators of individual typological properties of the higher nervous activity and sensorimotor functions of basketball players

\begin{tabular}{|c|c|c|c|c|}
\hline \multirow[t]{2}{*}{ № } & \multirow{2}{*}{ Test } & \multirow{2}{*}{ Parameter } & \multicolumn{2}{|c|}{ Statistical indicator } \\
\hline & & & $\bar{x}$ & $\sigma$ \\
\hline \multirow[t]{2}{*}{1.} & \multirow{2}{*}{$\begin{array}{l}\text { SVMR simple } \\
\text { visual-motor } \\
\text { reaction }\end{array}$} & Time of latent period (msec) & 365,36 & 51,19 \\
\hline & & Amount of mistakes & 2,00 & 1,33 \\
\hline \multirow[t]{2}{*}{2.} & \multirow{2}{*}{$\begin{array}{l}\text { RS1-3 reaction } \\
\text { select one of } \\
\text { the three } \\
\text { signals }\end{array}$} & Time of latent period (msec) & 501,18 & 34,76 \\
\hline & & Amount of mistakes & 1,55 & 1,29 \\
\hline \multirow[t]{2}{*}{3.} & \multirow{2}{*}{$\begin{array}{l}\text { RS2-3 reaction } \\
\text { select two of } \\
\text { the three } \\
\text { signals }\end{array}$} & Time of latent period (msec) & 527,64 & 37,14 \\
\hline & & Amount of mistakes & 2,64 & 2,01 \\
\hline \multirow[t]{5}{*}{4.} & \multirow{5}{*}{$\begin{array}{l}\text { LFM NP level } \\
\text { of functional } \\
\text { mobility of } \\
\text { nervous } \\
\text { processes }\end{array}$} & Time of latent period (msec) & 430,91 & 29,08 \\
\hline & & Amount of mistakes & 23,09 & 4,13 \\
\hline & & $\begin{array}{l}\text { Minimum time of signal exposure } \\
(\mathrm{msec})\end{array}$ & 380,00 & 51,38 \\
\hline & & Total time of test (sec) & 109,55 & 13,73 \\
\hline & & Minimum exposure time (sec) & 69,82 & 12,77 \\
\hline \multirow[t]{2}{*}{5.} & \multirow{2}{*}{$\begin{array}{l}\text { PNP } \\
\text { power of }\end{array}$} & Time of latent period (msec) & 394,64 & 15,58 \\
\hline & & Amount of mistakes & 293,64 & 15,36 \\
\hline
\end{tabular}




\begin{tabular}{|l|l|l|c|c|}
\hline \multirow{2}{*}{$\begin{array}{l}\text { nervous } \\
\text { processes }\end{array}$} & $\begin{array}{l}\text { Minimum time of signal exposure } \\
(\mathrm{msec})\end{array}$ & 325,45 & 23,82 \\
\cline { 2 - 4 } & Minimum exposure time $(\mathrm{sec})$ & 135,91 & 31,61 \\
\hline
\end{tabular}

Analysis of indicators of individual neurodynamic properties of the athletes showed that the time of the latent period (LP) simple and complex visual-motor reactions during the five test tasks was changed variably. The lowest rate of LP was recorded during the test to determine the indicators of simple visual-motor reaction and the average for the group corresponded $365,36 \pm 51,19$ msec. It should be noted that in this group of surveyed athletes, the minimum and maximum values of LP, as well as some recorded values of individual typological properties of higher nervous activity and sensorimotor functions of basketball players differ significantly from each other. This is explained by the fact that although the subjects are at the training stage of long-term training, they are not highly qualified athletes, and their team was formed from among the students of the University, whose level of psychophysiological condition is not the same. Thus, minimal value of LP SVMR was 296 msec, maximum - $432 \mathrm{msec}$. Average index of LP of simple and complex visual-motor reactions differs. So LP of reaction select one of the two signals (RS1-2) on average, the group corresponded to $501,18 \pm 34,76 \mathrm{msec}$, minimum value of LP RS1-2 - $446 \mathrm{msec}$, maximum - $537 \mathrm{msec}$. In the next test, more difficult - reaction of select two of the three signals (RS2-3) the index of athletes has also increased. Average time of LP SR2-3 $527,64 \pm 37,14 \mathrm{msec}$, minimal time - $466 \mathrm{msec}$, maximal- $574 \mathrm{msec}$. Regarding the errors in this test, the average is $2,64 \pm 2,01$, maximum index was 6 and minimum - 0 mistakes.

Averag index or LP level of functional mobility of nerve processes (LFMNP) was equal to $430,91 \pm 29,08$ and this is significantly different from LP of RS2-3 $(p<0,05)$, at the same time the minimum indicator corresponds to $395 \mathrm{msec}$ and the maximum is $480 \mathrm{msec}$. The number of mistakes has increased significantly during this test $-23,09 \pm 4,13$ mistakes and significantly different from those in SVMR, SR1-3 and SR2-3 tests $(p<0,05)$. The average total time of the test, which characterizes the level of mobility of nervous processes, was equal to $109,55 \pm 13,73 \mathrm{sec}$, maximum and minimum - $133 \mathrm{sec}$ и $91 \mathrm{sec}$ accordingly Analyzing this value of individual typological properties of higher nervous activity and sensorimotor functions of athletes, it should be noted that the lower the index, the higher the level of functional mobility of nervous processes.

In the final test (PNP), the LP rate on average for the group significantly decreased compared to the indicators of LP of SR1-2, SR2-3 and LFMNP and was equal to $394,64 \pm 15,58 \mathrm{msec}$. It should be noted that the duration of the test was 5 minutes, i.e. the tasks were carried out in the mode of accumulated fatigue. However, in the group of athletes recorded the maximum value that corresponds to $422 \mathrm{msec}$, minimum - $369 \mathrm{msec}$ and also, these data are below the corresponding indicators of LP of SR1-2, SR2-3, LFMNP. Analysis of the data obtained individually-typological properties of HNA surveyed basketball players indicate that the vast majority of surveyed athletes have a strong and mobile type of higher nervous activity.

The results of pedagogical tests aimed at determining the effectiveness of throws the ball into the basket showed that in some tests, the maximum and minimum values differ significantly (table 2).

Table 2. The results of pedagogical tests aimed at determining the effectiveness of throws $(n=24)$

\begin{tabular}{|c|c|c|c|c|}
\hline \multirow{2}{*}{ Tests } & \multicolumn{4}{|c|}{ Statistical indicator } \\
\cline { 2 - 5 } & $\bar{x}$ & $\sigma$ & $\min$ & $\max$ \\
\hline Two-point shots from given points, number of & 5,24 & 1,13 & 7,00 & 3,00 \\
\hline
\end{tabular}




\begin{tabular}{|l|r|r|r|r|}
\hline hits from 10 & & & & \\
\hline Average throws, number of throws per 40 sec & 9,40 & 0,76 & 11,00 & 8,00 \\
\hline Average throws, number of hits per 40 sec & 5,00 & 1,55 & 9,00 & 3,00 \\
\hline Free throw, number of hits from 10 & 5,80 & 1,13 & 9,00 & 3,00 \\
\hline $\begin{array}{l}\text { Three-point shots from given points, number of } \\
\text { hits from 10 }\end{array}$ & 3,96 & 1,06 & 5,00 & 2,00 \\
\hline Shots in the jump, number of hits from 10 & 4,00 & 1,26 & 7,00 & 2,00 \\
\hline $\begin{array}{l}\text { Throws from given points (40 throws per 3.5 min, } \\
\text { amount of efficient throws) }\end{array}$ & 19,00 & 3,65 & 26,00 & 14,00 \\
\hline Throws during 5 min, amount of throws & 43,96 & 4,66 & 52,00 & 33,00 \\
\hline Throws during 5 min, amount of effective throws & 21,20 & 1,94 & 24,00 & 16,00 \\
\hline
\end{tabular}

It should be noted that despite the fact that there are pronounced differences between the maximum and minimum values in general for 6 indicators in testing, the examined group is homogeneous in terms of the coefficients of variation for six indicators $(\mathrm{V}<20 \%)$.

Analysis of scientific and methodological literature on the relationship of development, manifestations of psychophysiological functions and technical skills of basketball players showed sufficient coverage of these issues, but the available data are fragmentary. To a greater extent, they are related to the study of individual components of the psychophysiological state of basketball players of different ages and sports qualifications, in particular, the most common scientific articles on the impact of stress and anxiety of the athlete on the accuracy of throws in basketball, the analysis of indicators of simple and complex visual-motor reaction depending on the role of athletes $[13,15,20]$. In our research, in order to determine the relationship between the psychophysiological state and the effectiveness of the throws of basketball players, a correlation analysis of the indicators of psychophysiological and pedagogical testing was carried out.

Correlation analysis of indicators of individual-typological properties of higher nervous activity and sensorimotor functions with indicators of throws of basketball players allowed to reveal how the studied values are connected with each other. Thus, the correlation groups presented in figure 2-3 demonstrate tests with high and medium correlation coefficients. As the analysis of the studied parameters shows, all tests have a high and average relationship with each other, but some with more tests, some with less. For example, indicators of LP SVMR correlates with high connection with four (correlation coefficient-r was in the range from $-0,743$ till $-0,817, \mathrm{p}<0,01)$ and with average $(\mathrm{r}=0,581, \mathrm{p}<0,05)$ with one record in five tests of throwing the ball into the basket (figure 1). 


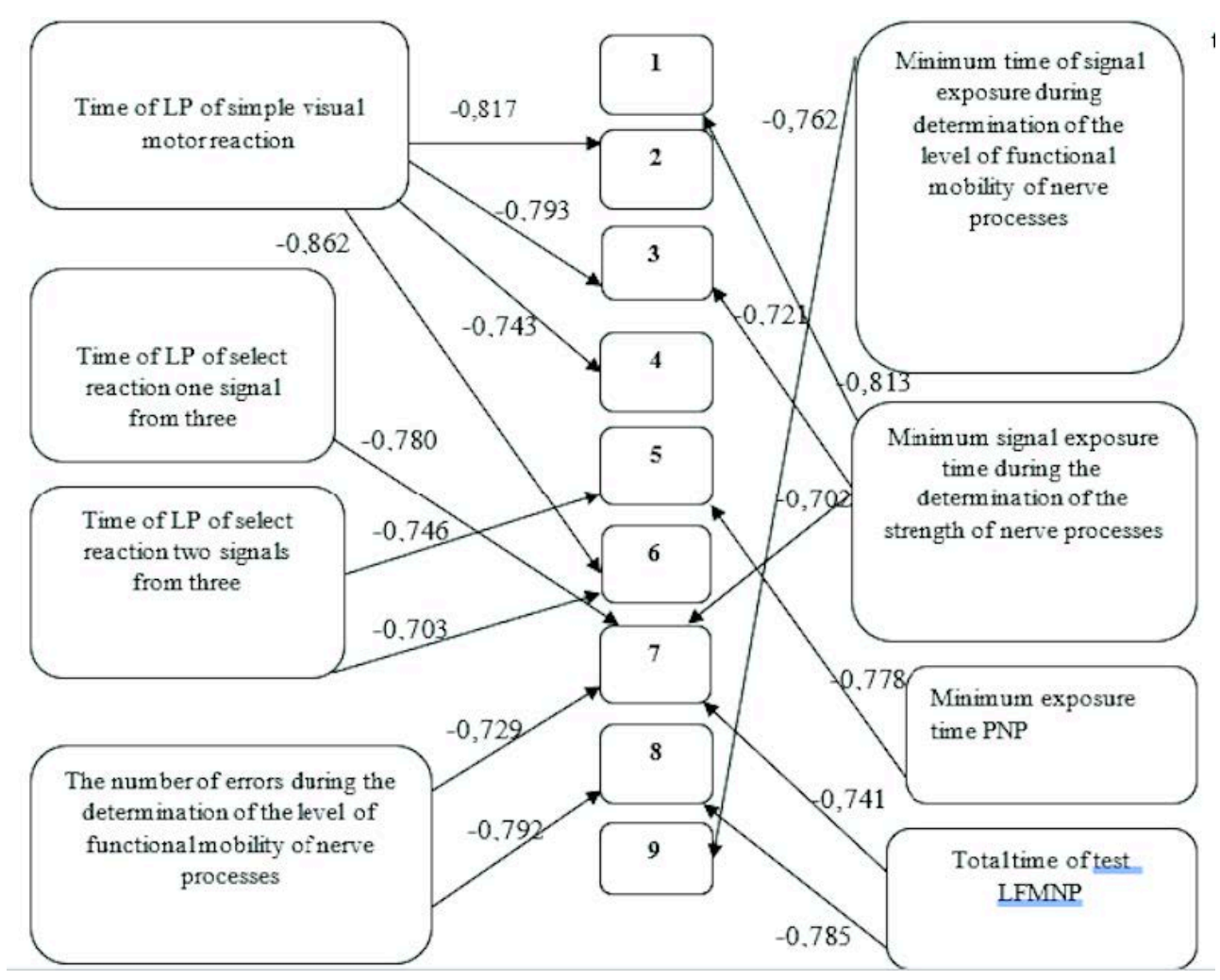

Figure 1. Correlation group with high level connection of index of individual and typological properties of the higher nerve system and sensorimotor functions with the efficiency of throws: 1 amount of hits of two-point throws from 10 (from given throws on perimeter of 3-sec zone); 2 amount of average throws per $40 \mathrm{sec} ; 3$ - amount of effective average throws for $40 \mathrm{sec} ; 4$ - a number of effective free throws from 10;5- amount of effective three-point throws from 10;6-a number of effective throws in the jump from 10; 7- a number of effective shots from given points (40 throws for 3,5 min of total test time); 8 - a number of shots for 5 min.; 9 - a number of scoring shots for $5 \mathrm{~min}$; LFMNP - level of functional mobility of nervous processes, PNP - power of nervous process

According to the results of correlation analysis of the effective throws the ball to the basket and psycho-physiological status of basketball players are closely related, which is confirmed by the results of correlation analysis of the values of psychophysiological and pedagogic testing, namely, indicators of individual-typological characteristics of the higher nervous activity and sensory-motor functions and performance of nine tests to determine the effectiveness of the shots of students who play basketball. The negative correlation coefficients obtained indicate feedback. In this case, the lower the index in psychophysiological testing, except for the number of exposures of PNP, the higher the effectiveness of ball throws athletes. It should be noted that the strongest relationship is revealed between the effectiveness of throws the ball into the basket and the values of individual typological properties of higher nervous activity and sensorimotor functions, such as LP SVMR, LP RS1-3, RS2-3, amount of errors LFMNP, total test time of LFMNP, minimal time of signal exposition LFBNP, minimal time of signal exposition of PNP, minimum exposure time PNP. 


\section{References}

1. G.V. Korobeynikov. Sport medicine. 1. 33-36. (2006)

2. G.V. Korobeynikov. Psychophysiological organization of human activity (Belaya Tserkov', 2008)

3. D.S. Melnikov, V.V. Seliverstova, Psychophysiological testing of athletes (National State University of Physical Culture, Sports and Health named after P.F. Lesgaft, St. Petersburg, 2010)

4. G.V. Korobeynikov, S.M. Bitko, L.D. Sakal. Collection of scientific works. 53-60 (2003)

5. G.V. Korobeynikov. L.G. Korobeynikova, J.L.Kozina. Estimation and correction of athletes' psychophysiological condition (2012)

6. Ju.M. Bludov, V.A. Plahtiennko, Reliability in sports (Physical culture and sports, Moscow, 1983)

7. V.M. Rizhov, V.P.Salnitsky. Space biology and aerospace medicine. 5, 83-84 (1983)

8. E.N.Surkov, Psychomotor of athletes (Physical culture and sports, Moscow, 1984)

9. A.A. Asknazij, On the correlation of changes in the functional state of the nervous system during sports training (Physical culture and sports, Moscow, 1969)

10. V.Z.Babushkin, Specialization in sport games (Health, Moscow, 1991)

11. L.S.Vysokov, Collection of scientific works. 45-50 (1987)

12. P.J.K. Smith, M.E. Rudisill. Reseach quaterly for exercise and sport. 62, 151-157 (1993)

13. S.M. Aglioti, P Cesari, M. Romani, C. Urgesi, Nature neuroscience. 11(9), 1109$1116(2008)$

14. Ç. Dereceli Journal of Education and Training Studies. 6;7(1), 17-22 (2018)

15. V.A. Troshikhin, S.I. Moldavskaya, N.V. Kolchenko, Functional mobility of nervous processes and professional selection (Scientific thought, 1978)

16. G.V. Korobeynikov, L.G. Korobeynikova, L.V. Romanyuk, N.A. Dakal, G.V. Danko, Pedagogics, psychology, medical-biological problems of physical training and sports. 21(6), 272-278 (2017)

17. G.V. Korobeynikov, V.V. Myshko. Pedagogics, psychology, medical-biological problems of physical training and sports. 4, 17-22 (2016)

18. G.V. Korobeynikov et al., Archives of Budo. 6(3), 129-136 (2010)

19. N.V. Makarenko, J Physiology. 45, 125-311 (1999)

20. Jr E.P. Paula, D.L. Paza, G.C. Pierozan, J.M. Stefanello, Journal of Exercise Physiology Online 19(6), 111-122 (2016) 